\title{
The hexane fraction of Naematoloma sublateritium extract suppresses the TNF- $\alpha$-induced metastatic potential of MDA-MB-231 breast cancer cells through modulation of the JNK and p38 pathways
}

\author{
YU RAN LEE $^{1 *}$, KI MO KIM $^{2 *}$, BYEONG HWA JEON $^{1}$ and SUNGA CHOI $^{1}$ \\ ${ }^{1}$ Department of Physiology, School of Medicine, Chungnam National University, Daejeon 301747; \\ ${ }^{2}$ Cancer Research Team, Korean Medicine Based Herbal Drug Research Group, Herbal Medicine Research Division, \\ Korea Institute of Oriental Medicine (KIOM), Daejeon 305811, Republic of Korea
}

Received April 22, 2014; Accepted June 11, 2014

DOI: 10.3892/ijo.2014.2526

\begin{abstract}
Naematoloma sublateritium (Fr.) P. Karst is a basidiomycete that has been used as traditional medicine. $N$. sublateritium produces a triterpenoid antitumor compound, clavaric acid, but, in general, the effects of $N$. sublateritium constituents against tumor invasion and metastasis have been poorly studied. To investigate the inhibitory effect of N. sublateritium constituents on highly invasive and metastatic tumor cells, the TNF- $\alpha$-stimulated human breast cancer cell line, MDA-MB-231 was treated with the hexane fraction of an N. sublateritium extract (HFNS). Non-cytotoxic concentrations of HFNS markedly inhibited the invasion and migration of the MDA-MB-231 cells in the Matrigel invasion assay and wound-healing analysis, respectively. Gelatin zymography showed that HFNS suppressed the activity of MMP-9, but not of MMP-2. Immunoblotting demonstrated that treatment with HFNS had decreased the level of MMP-9 and urokinase plasminogen activator-1 (uPA-1), but had upregulated expression of the endogenous inhibitor proteins, including TIMP-1,-2, and PAI-1, in a dose-dependent manner. Furthermore, HFNS suppressed the phosphorylation of p38 and JNK1/2, but not that of ERK1/2. This was confirmed by pretreatment of cells with specific inhibitors prior to stimulation with TNF- $\alpha$. HFNS treatment also led to a dose-dependent inhibition of the DNA-binding activities of AP-1 and NFKB, which are downstream targets of JNK and p38. These data suggested that
\end{abstract}

Correspondence to: Dr Sunga Choi, Department of Physiology, School of Medicine, Chungnam National University, 55 Munhwa-ro, Jung-gu, Daejeon 301747, Republic of Korea

E-mail: sachoi@cnu.ac.kr

${ }^{*}$ Contributed equally

Key words: anti-metastatic effect, breast cancer cells, hexane fraction, MAPK pathway, Naematoloma sublateritium
HFNS inhibits the metastatic potential of MDA-MB-231 cells by inhibiting the phosphorylation of $\mathrm{JNK} / \mathrm{p} 38$ and reducing AP-1 and NFкB DNA-binding activities. Therefore, HFNS may be a potential therapeutic agent against metastasis of breast cancer.

\section{Introduction}

Despite years of research and development of various therapies, cancer remains one of the major causes of mortality worldwide. Breast cancer is a leading cause of cancer-related deaths amongst women globally. Recently, the increasing incidence of breast cancer has slowed down, but this varies between countries, due to differences in reproductive and hormonal factors, and the availability of early diagnostic services (1). There has also been an increase in the breast cancer mortality rate, which is probably caused by improper treatment, the poor prognosis related to metastatic cancer, and recurrence of cancer after surgery $(2,3)$. Metastatic breast cancer could spread beyond the original organ, to bone, liver, lung, and brain, causing secondary cancers; for example, breast cancer cells that metastasize is considered invasive breast cancer, not lung cancer.

Tumor metastasis proceeds by sequential and selective steps including cell adhesion, uncontrolled proliferation, formation of the malignant phenotype, detachment from the primary site, invasion into the connective tissue and circulation, and extravasation into the organ parenchyma $(4,5)$. A crucial step during migration and invasion, which results in a secondary tumor at a distant site is the degradation of environmental barriers, such as the extracellular matrix and the basement membrane, by various proteolytic enzymes, called matrix metalloproteinases (MMPs). MMPs are a family of secretory membrane-anchored proteases and are directly activated by the serine protease plasmin, which is produced from plasminogen by the serine protease urokinase-type plasminogen activator-1 (uPA-1) (6). It has been found that MMP-2, -9 and uPA-1 are highly expressed in cancerous organs, including breast tissue, and, together, they are associated with invasiveness and 
progression of breast cancer (7-11). Tumor necrosis factor- $\alpha$ (TNF- $\alpha$ ) also regulates tumor remodeling by stimulating cell motility and invasion, via induction of MMPs $(8,12,13)$. The activities of MMPs and of proteolytic uPA-1 are modulated by tissue inhibitors of metalloproteinases (TIMPs) and plasminogen activator inhibitor (PAI), respectively; this protects the basement membrane against excessive degradation (14-16). Therefore, regulation of the expression of MMPs and TIMPs and/or regulation of uPA-1-mediated migration or invasion could be considered as a potential treatment for preventing or inhibiting cancer metastasis.

Exploration of novel therapeutic drugs for the treatment of advanced, recurrent, and metastatic breast cancer carries a high priority. Many studies have reported that natural products, dietary phytochemicals, such as sulforaphane and isothiocyanates from broccoli and watercress $(17,18)$, tea catechins $(19)$, genistein, apigenin (20), ganoderic acid from the Ganoderma lucidum mushroom (21), and Phellinus linteus $(22,23)$ have a variety of anticancer, anti-invasive, and anti-metastatic activities. Naematolma (Syn. Hypoloma) spp. are basidiomycete that are known to produce an antitumor compound, clavaric acid (24-26). In our previous studies, we reported the highperformance liquid chromatography (HPLC) profiles and biological functions including, anti-oxidative, anti-inflammatory, and anticancer activities against various cancer cells of N. sublateritium extracts $(27,28)$. Particularly, among fractions sequentially prepared from $N$. sublateritium ethanol extract, hexane fractions (HFNS) and the dichloromethane fraction of $N$. sublateritium exhibited the ability to inhibit cell proliferation and viability of triple-negative breast cancer cell line (TNBC), MDA-MB-231 (27).

These observation led us to consider whether the activity of HFNS also extend to modulation of metastatic potential. Thus, in the present study, we investigated the effects of HFNS on the motility and migration of MDA-MB-231 cells along with its ability to modulate the regulatory proteins MMP-2, MMP-9, uPA-1, TIMP, and PAI. Furthermore, the influence of HFNS on the MAPK signaling, which is related to MMPs activation (29) through regulation of the transcriptional factors nuclear factor- $\kappa \mathrm{B}(\mathrm{NF} \kappa \mathrm{B})$ and activator protein-1 (AP-1), was also investigated. The results of our study indicate the significant potential of HFNS as a preventive agent against the occurrence or metastasis of TNBC.

\section{Materials and methods}

Materials. The human breast cancer cell line, MDA-MB-231 was obtained from the Korean Cell Line Bank (Seoul, Korea). RPMI-1640 medium, fetal bovine serum (FBS), and antibiotics were purchased from Gibco (Grand Island, NY, USA). Human TNF- $\alpha$, 3-(4, 5-dimethylthiazol-2-yl)-2,5-diphenyltetrazolium bromide (MTT), dimethyl sulfoxide (DMSO) and anti $\beta$-actin antibody were purchased from Sigma (St. Louis, MO, USA). Antibodies against MMP-2, MMP-9, TIMP-1, TIMP-2, PAI-1, phospho-JNK1/2, phospho-ERK1/2, and phospho-p38 were obtained from Cell Signaling Technology (Beverly, MA, USA). Antibodies against uPA-1, JNK1/2, ERK, and p38 were purchased from Santa Cruz Biotechnology (Santa Cruz, CA, USA). Cultrex basement membrane extract (BME) cell invasion assay kit and gelatin precast gels were from Trevigen Inc.
(Gathersburg, MD, USA) and Bio-Rad (Hercules, CA, USA), respectively.

Preparation of HFNS. The ethanolic extract of N. sublateritium was prepared as described (28). The extract was sequentially fractionated using the organic solvents, hexane, dichloromethane, n-butanol and ethyl acetate. The hexane fraction was concentrated, passed through a $0.2-\mu \mathrm{m}$ filter and dried using a freeze-drier. Dried HFNS was reconstituted in vehicle for cell culture studies. The HPLC chromatogram of HFNS confirmed the non-polar characteristics of the extract at late retention times (27)

Proliferation and viability assay. Monolayer cultures of MDA-MB-231 cells were maintained in RPMI-1640 medium supplemented with $10 \%$ (v/v) FBS and antibiotics. Cells were maintained in an atmosphere of $95 \%$ air and $5 \% \mathrm{CO}_{2}$ at $37^{\circ} \mathrm{C}$. The effect of HFNS on cell proliferation and viability was determined by the MTT colorimetric method and propidium iodide (PI) staining, respectively (27). Cells were treated with DMSO (control) or HFNS for 24 or $48 \mathrm{~h}$. Results are expressed as the ratio of the number of live cells with HFNS treatment relative to that observed after DMSO-treatment.

Wound-healing assay. Cells were plated in a 6-well plate and allowed to form a confluent monolayer for $24 \mathrm{~h}$. Cells were then serum starved for $24 \mathrm{~h}$ and the monolayer in each cell was scratched with a pipette tip, and washed with serum-free medium to remove floating cells. Cells were then treated with TNF- $\alpha(20 \mathrm{ng} / \mathrm{ml})$ in the presence of various concentrations of HFNS for $18 \mathrm{~h}$. The cells were allowed to migrate across the scratch, and photographed at three randomly selected sites per well through an inverted microscope (x40 magnification).

Invasion assay. The invasion assay was performed using Cultrex ${ }^{\circledR}$ 96-well BME Cell invasion assay kit. Briefly, duplicate transwell chambers with $8-\mu \mathrm{m}$ pore polycarbonate filters were coated with $50 \mu \mathrm{l}$ of ice-cold $0.8 \mathrm{X}$ BME in coat buffer and incubated overnight at $37^{\circ} \mathrm{C}$. To monitor cell migration, $1 \times 10^{5}$ cells were seeded on to BME-coated filter, which was then inserted into the upper chamber, containing serum-free media. The lower chamber was filled with $500 \mu \mathrm{l}$ of medium containing TNF- $\alpha$, as well as various concentrations of HFNS. The control well contained media only. After incubation for $24 \mathrm{~h}$, the cells on the underside of the filter were quantified using Calcein-AM according to the assay kit manual. Cells that had migrated to the bottom of the membrane were visualized and counted using an inverted fluorescence microscope.

Gelatin zymography assay. The activities of MMP-2 and MMP-9 medium released from MDA-MB-231 cells into the medium were measured using a gelatin zymography protease assay. Cells were serum starved for $18 \mathrm{~h}$ and then treated with TNF- $\alpha$ or TNF- $\alpha$ combined with HFNS for the indicated time or concentration for $12 \mathrm{~h}$. The cell culture medium was then collected and concentrated using Microcon YM-10 filters (Millipore, Billerica, MA, USA). The concentrated sample was subjected to electrophoresis on $7 \%$ polyacrylamide gels containing gelatin, in the absence of a reducing agent. 
Table I. PCR primers.

\begin{tabular}{|c|c|c|c|c|c|}
\hline $\begin{array}{l}\text { Target } \\
\text { genes }\end{array}$ & & Primer sequences & Size (bp) & $\begin{array}{c}\text { Annealing } \\
\text { temperature }\left({ }^{\circ} \mathrm{C}\right)\end{array}$ & Cycle \\
\hline PAI-1 & $\begin{array}{l}\text { Sense } \\
\text { Antisense }\end{array}$ & $\begin{array}{l}\text { 5'-TGCTGGTGAATGCCCTCTACT-3' } \\
\text { 5'-TAGAGAACCTGGGAATGACCG-3' }\end{array}$ & 399 & 58 & 28 \\
\hline uPA-1 & $\begin{array}{l}\text { Sense } \\
\text { Antisense }\end{array}$ & $\begin{array}{l}\text { 5'-CACGCAAGGGGAGATGAA-3' } \\
\text { 5'-AAGTCACCACCAAAATGCTGT-3' }\end{array}$ & 341 & 58 & 28 \\
\hline TIMP-1 & $\begin{array}{l}\text { Sense } \\
\text { Antisense }\end{array}$ & $\begin{array}{l}\text { 5'-CTTCCACAGGTCCCACAACC-3' } \\
\text { 5'-GCCTCGGGAGCCAGGGCTG-3' }\end{array}$ & 304 & 60 & 30 \\
\hline TIMP-2 & $\begin{array}{l}\text { Sense } \\
\text { Antisense }\end{array}$ & $\begin{array}{l}\text { 5'-GATGCACATCACCCTCTGTGA-3' } \\
\text { 5'-AGAACATCAACGGGCAC-3' }\end{array}$ & 196 & 52 & 30 \\
\hline MMP-9 & $\begin{array}{l}\text { Sense } \\
\text { Antisense }\end{array}$ & $\begin{array}{l}\text { 5'-GCACGACGTCTTCCAGTACC-3' } \\
\text { 5'-ACCTATGACATCCTGCAGTGC-3' }\end{array}$ & 130 & 58 & 28 \\
\hline$\beta$-actin & $\begin{array}{l}\text { Sense } \\
\text { Antisense }\end{array}$ & $\begin{array}{l}\text { 5'-AGCAGAGAATGGAAAGTCAAA } \\
\text { 5'-ATGCTGCTTACATGTCTCGAT-3' }\end{array}$ & 490 & 55 & a \\
\hline
\end{tabular}

${ }^{a}$ The cycle of $\beta$-actin as an internal control was adjusted to that of each target gene.

Immunoblotting. Cells were treated with different HFNS concentrations in the presence of TNF- $\alpha$ for the indicated time. The cell culture medium was collected and concentrated. Cell lysates were prepared by centrifugation at $12,000 \mathrm{x} \mathrm{g}$ for $20 \mathrm{~min}$, as previously described (18). Proteins were resolved on SDS-PAGE and transferred onto a PVDF membrane. Immunoblotting was performed with antibodies specific for uPA-1 PAI-1, TIMP-1, TIMP-2, MMP-2 and MMP-9. Changes in total protein level and phospho-JNK1/2, phospho-ERK1/2, and phospho-p38 levels were also determined using specific antibodies. The immunoreactive bands were visualized using enhanced chemiluminescence. The band intensity was quantified using a densitometer followed by normalization to the density of $\beta$-actin.

Semi-quantitative reverse transcription-PCR. MDA-MB-231 cells were treated with TNF- $\alpha$ or TNF- $\alpha$ plus HFNS of the indicated concentration and for the indicated time, and then total RNA was extracted using the BCP Phase Separation Reagent (MRC Inc., Cincinnati, OH, USA). The RNA was converted to cDNA using a reverse transcription-PCR kit containing oligo(dT) primers (Intron Biotech., Seoul, Korea) according to the manufacturer's protocol (28). The primers and PCR conditions are listed in Table I. PCR products were electrophoresed on $1 \%$ agarose gels and visualized under ultraviolet light after ethidium bromide staining.

Electrophoretic mobility shift assay for $A P-1$ and $N F \kappa B$. Cells were treated with the different HFNS concentrations in the presence of TNF- $\alpha$. Nuclear extracts of the cells were prepared and the proteins were subjected to electrophoretic mobility shift assays (EMSA) as previously described (28). Briefly, $2 \mu \mathrm{g}$ of nuclear extract was combined with $0.25 \mathrm{mg} / \mathrm{ml}$ poly(dI)-poly(dC)-non-specific competitor in Gel Shift binding buffer (20\% glycerol, $5 \mathrm{mM} \mathrm{MgCl}_{2}, 2.5 \mathrm{mM}$ EDTA, $2.5 \mathrm{mM}$
DTT, $250 \mathrm{mM} \mathrm{NaCl}$, and $50 \mathrm{mM}$ Tris-HCl); to this was added IRDye 700-labeled AP-1 or NFאB oligonucleotide (LI-COR Inc., Lincoln, NE, USA). After incubation at room temperature for $30 \mathrm{~min}$, the protein-DNA complexes were separated from the free probe on a pre-run $8 \%$ polyacrylamide gel. The signal was then detected and quantified using the Odyssey Infrared Imaging System (LI-COR Inc.).

Statistical analysis. Differences in the measured variables between the control and HFNS-treated groups were determined using a one-way analysis of variance (ANOVA) followed by Dunnett's or Bonferroni's test for multiple comparisons. $\mathrm{P}$-values of $<0.05$ were considered significant.

\section{Results}

Effect of HFNS on the viability and proliferation of TNF- $\alpha$ stimulated MDA-MB-231 cells. In a previous study, we observed that HFNS significantly inhibited growth of various human cancer cell lines (27). The HFNS concentration required for $50 \%$ inhibition of viability and proliferation of MDA-MB-231 cells was $200 \mu \mathrm{g} / \mathrm{ml}$ for a $24 \mathrm{~h}$ treatment. To verify the effects of HFNS, MDA-MB-231 cells were exposed to different concentrations of HFNS and were then stimulated with TNF- $\alpha$ for 24 or $48 \mathrm{~h}$. As shown in Fig. 1, the viability of MDA-MB-231 cells was not affected by up to $100 \mu \mathrm{g} / \mathrm{ml}$ HFNS treatment, indicating that these were non-cytotoxic concentrations of HFNS in the presence of TNF- $\alpha$. A significant decrease in cell viability was observed after a $24 \mathrm{~h}$ exposure of $200 \mu \mathrm{g} / \mathrm{ml}$ HFNS: cell viability was reduced by $\sim 39.7 \%$ relative to that of cells treated with TNF- $\alpha$ only (Fig. 1A). The MTT assay indicated that proliferation of MDA-MB-231 cells was markedly inhibited by HFNS treatment, even at $50 \mu \mathrm{g} / \mathrm{ml}$ for $24 \mathrm{~h}$, confirming the anti-proliferating activity of HFNS on MDA-MB-231 cells (Fig. 1B). These results suggested 
A

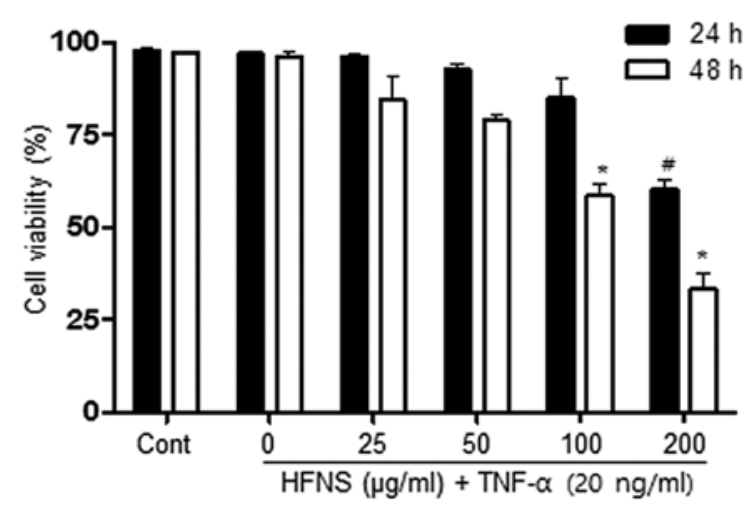

B

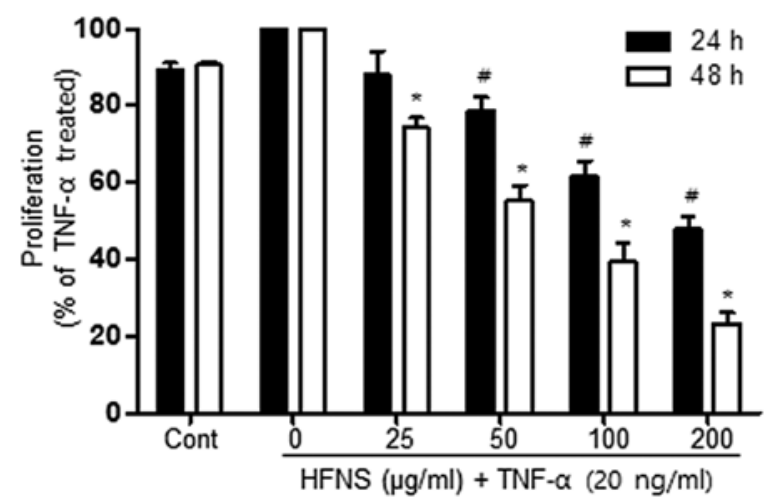

Figure 1. Effect of HFNS on the viability and proliferation of MDA-MB-231 cells. (A) The MDA-MB-231 human breast cancer cell line was treated with increasing concentrations of HFNS for 24 or $48 \mathrm{~h}$. The effects of HFNS at the indicated concentrations on the viability of MDA-MB-231 cells was determined by propidium iodide (PI) staining and was compared with those on the viability of TNF- $\alpha$-stimulated controls. (B) Cell proliferation was analyzed using an MTT assay. Data are presented as means \pm SEM $(n=3)$. ${ }^{*} \mathrm{P}<0.05$, significantly different compared with control, by one-way ANOVA followed by Dunnett's test. Similar results were observed in replicate experiments.

that the change in cell viability observed at $100 \mu \mathrm{g} / \mathrm{ml} \mathrm{HFNS}$ can be attributed mainly to the inhibition of proliferation. Moreover, HFNS could regulate the metastatic properties of MDA-MB-231 cells without causing significant cell death.

HFNS inhibits migration and invasion of TNF- $\alpha$-stimulated $M D A-M B-231$ cells. Next, we investigated the effects of HFNS on TNF- $\alpha$-stimulated MDA-MB-231 cells, considering the highly invasive nature of TNBC. We investigated whether HFNS could inhibit the migration and invasive potential of TNF- $\alpha$-stimulated MDA-MB-231 cells, using a wound-healing repair assay and an in vitro transwell assay, respectively. After cell monolayers were wounded in the repair assay, TNF- $\alpha$ treated cells migrated to the cleared area, but treatment with HFNS dose-dependently inhibited TNF- $\alpha$-stimulated migration of MDA-MB-231 cells (Fig. 2A). Moreover, the invasive activity of MDA-MB-231 cells was significantly regulated by HFNS treatment in a dose-dependent manner. As shown in Fig. 2B, in the transwell chamber assay, HFNS induced a decrease in the fluorescence of MDA-MB-231 invasive cells in the lower chamber, reached through a Matrigel-coated membrane. More specifically, the fluorescent intensity was reduced by $51.4 \%$ relative to that seen with $\mathrm{TNF}$ - $\alpha$-treated control cells following a $24 \mathrm{~h}$ exposure to $50 \mu \mathrm{g} / \mathrm{ml}$ of HFNS. These results indicated that HFNS has an inhibitory effect on the migration and invasiveness of TNF- $\alpha$-stimulated MDA-MB-231 cells.

Inhibition of MMP activity by HFNS. Because MMPs have emerged as critical regulators of metastasis, by their role in degrading the basement membrane, we investigated the effect of HFNS treatment on the activity of secreted MMP-9 and MMP-2 in TNF- $\alpha$-stimulated MDA-MB-231 cells. The effect of HFNS on the gelatinase activity of MMP-2 and MMP-9 was analyzed using zymogram gels containing gelatin, the preferred substrate. The activity of MMPs present in the cell culture supernatant was identified by digestion of the substrate at a molecular weight corresponding to that attribute to specific MMPs (MMP-9: $92 \mathrm{kDa}$ ), which is seen as a clear band.

As can be seen in Fig. 3, in conditioned medium from cells treated with only TNF- $\alpha$, the intensity of the MMP-9 band was decreased in a dose- and time-dependent manner. Treatment of cells with $100 \mu \mathrm{g} / \mathrm{ml}$ HFNS resulted in a rapid decrease in the intensity of this band ( $\sim 34.2 \%$ decrease, compared to the levels of the TNF- $\alpha$-treated control cells) within $2 \mathrm{~h}$, indicating inhibition of MMP-9 activity. In contrast, no detectable amount of MMP-2 activity was seen with either TNF- $\alpha$ or HFNS treatment (Fig. 3B). This suggests that the inhibitory activity of HFNS on the migration and invasion of MDA-MB-231 cells may be due mainly to inhibition of MMP-9 activity.

Regulation of MMP-9, TIMP-2, uPA-1, and PAI-1 expression by HFNS treatment. Because HFNS treatment resulted in inhibition of MMP-9 activity, we also evaluated the secretion of MMP-9, MMP-2, uPA-1, and the MMP inhibitors, viz., TIMP-1, TIMP-2, and PAI-1 in MDA-MB-231 cells. In immunoblot analysis, the levels of MMP-9 and uPA-1 were significantly decreased by HFNS treatment, in accordance with the decreased MMP-9 activity. There were no noticeable changes in MMP-2 levels in TNF- $\alpha$ - or HFNS-treated MDA-MB-231 cells (data not shown).

The level of MMPs and UPA-1 are inversely related to the levels of TIMPs and PAIs, respectively. Interestingly, the treatment with HFNS induced a modest increase in levels of TIMP-2 and PAI-1 in a dose-dependent manner, although the change in the level of TIMP-2 was not statistically significant. However, upregulated TIMP 2 and $P A I-1$ at transcript level was also observed by semi-quantitative RT-PCR analysis after treatment of cells with HFNS (Fig. 4B).

Inhibition of MAPK signaling pathways by HFNS treatment. Previous reports have demonstrated that natural product-derived agents could regulate metastasis through suppression of MAPKs $(13,29,30)$. To gain insights into the mechanism underlying the anti-metastatic effects of HFNS in MDA-MB-231 cells, we investigated the MAPK signaling pathways, and determined the effects of HFNS on JNK, p38-MAPK, and ERK1/2 activation. In response to TNF- $\alpha$ stimulation, JNK and p38 proteins were phosphorylated within $30 \mathrm{~min}$ and the levels reached $\sim 2.7$ - and 5.1-fold those in the control cells, respectively (Fig. 5A). The activa- 
A

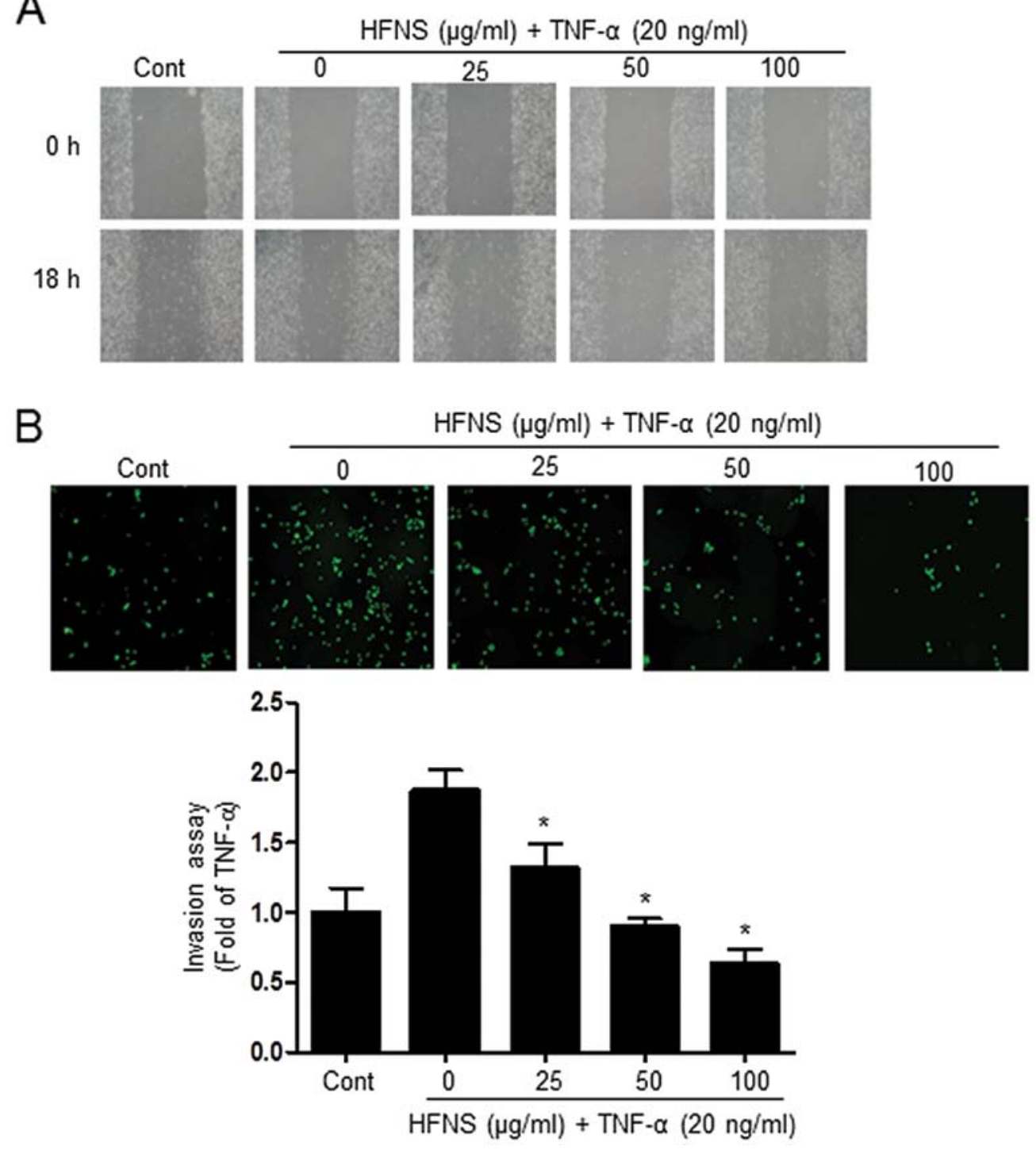

Figure 2. The inhibitory effects of HFNS on migration and invasion of TNF- $\alpha$-stimulated MDA-MB-231 cells. (A) Confluent monolayers of cells were scratched with a pipette tip and were then treated with either TNF- $\alpha(20 \mathrm{ng} / \mathrm{ml})$ alone, or TNF- $\alpha$ plus HFNS at the indicated concentrations. Cell migration into the wound was observed using a phase contrast microscope (x100 magnification) at 0 and $18 \mathrm{~h}$. (B) MDA-MB-231 cells were plated on a Matrigel membrane $(8-\mu \mathrm{m})$, and the insert was placed into a well containing TNF- $\alpha$ along with various concentrations of HFNS for $18 \mathrm{~h}$. The cells invading the membrane were photographed by fluorescent microscopy (x400 magnification). Quantification of the number of invading cells was obtained from three separate experiments. Data are expressed as the ratio to HFNS-treated cells. Columns, mean; bars, SE. ${ }^{*} \mathrm{P}<0.05$, significant difference from HFNS-treated cells ( $\mathrm{n} \geq 3$ ).

tion of p38 MAPK was prolonged for $>2 \mathrm{~h}$ after exposure to TNF- $\alpha$-simulated MDA-MB-231 cells (Fig. 5A), although JNK activation declined gradually. However, cells exposed to $100 \mu \mathrm{g} / \mathrm{ml}$ HFNS exhibited a rapid and complete inactivation of JNK and p38, which was not induced by changes in their total protein level (Fig. 5A). In contrast, phosphorylation of ERK was not affected by HFNS treatment or by the ERK inhibitor PD98059 (Fig. 5). These results indicated that HFNS-mediated supression of MAPKs was selective for the regulation of metastatic MDA-MB-231 cells.

Furthermore, we confirmed the functional significance of MAPK downregulation using pharmacologic inhibitors of JNK1/2 (SP600125), p38 MAPK (SB202190), and ERK1/2 (PD98059). The activation of MAPKs in response to TNF- $\alpha$ was attenuated by pretreatment of cells with SP600125 or SB202190, but not PD98059, indicating inactivation of JNK1/2 or p38, but not ERK1/2, respectively. The pharmacological inactivation of MAPK also caused downregulated expression and enzymatic inactivation of MMP-9 as shown in Fig. 5B. The results were comparable to those of HFNS-treated MDA-MB-231 cells. Collectively, these results pointed toward an important regulatory role for JNK1/2 and p38 MAPK antimetastatic effect of HFNS on MDA-MB-231 human breast cancer cells.

HFNS inhibits AP-1 and NFKB DNA binding activities. The expression of MMP-encoding genes is regulated by the transcription factors AP-1 or $\mathrm{NF \kappa B}(3,11,21,29)$, which are upregulated by TNF- $\alpha$ in a variety of cancer cell lines, including breast cancer cells $(28,31,32)$. To confirm whether the repressive effect of HFNS on TNF- $\alpha$-induced MMP-9 or UPA-1 expression is mediated via AP-1 or NFкB 

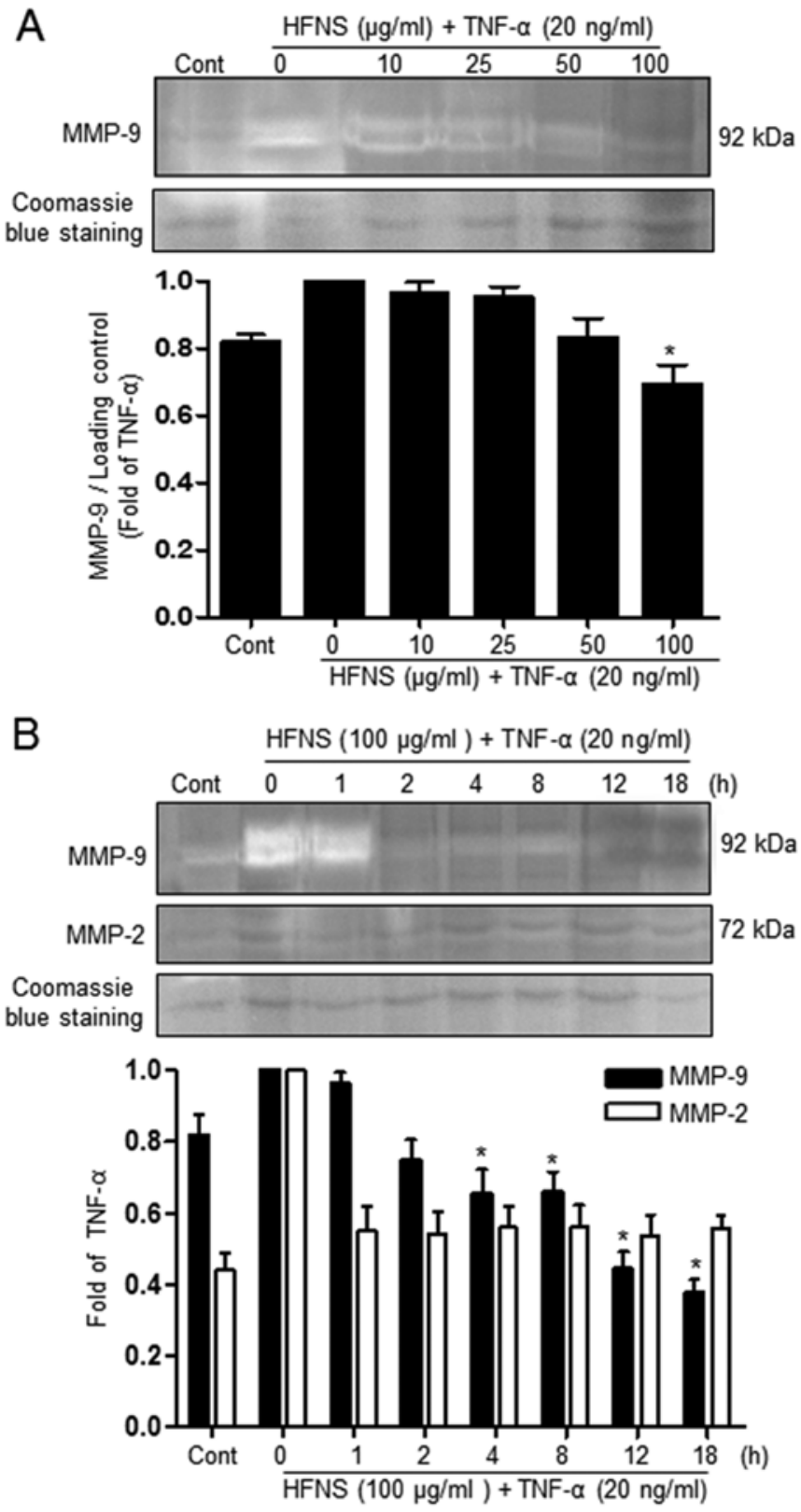

Figure 3. Modulation of metastatic proteins in TNF- $\alpha$-stimulated MDAMB-231 cells. (A,B) Inhibition of MMP-9 or MMP-2 activity in conditioned medium from MDA-MB-231 cells treated with HFNS at the indicated concentration and for the indicated time was evaluated using gelatin zymography. Bands were visualized on a Bio-Rad imaging system. Equa amounts of sample were electrophoresed, run on $7 \%$ acrylamide gels and gels were then stained with Coomassie Blue as loading control. Representative data from a single experiment is shown. Fold-changes in HFNS inhibitedMMP activity relative to TNF- $\alpha$-only-treated controls are shown for each point in a bar graph. *Significantly different $(\mathrm{P}<0.05)$ compared with TNF- $\alpha-$ only-treated control by one-way ANOVA followed by Dunnett's test. Similar results were observed in two independent experiments.

motifs, TNF- $\alpha$-stimulated MDA-MB-231 cells were dosedependently treated with HFNS for $18 \mathrm{~h}$. The DNA-binding activity of these transcription factors was then determined using nuclear extracts and EMSA, TNF- $\alpha$ treatment caused an increase in AP-1 and NFאB binding activity (Fig. 6A). The activity of $\mathrm{NF \kappa B}$ was markedly inhibited at treatment of cells with $100 \mu \mathrm{g} / \mathrm{ml}$ HFNS; more specifically, the initial TNF- $\alpha$-induced activation was followed by $25.4 \%$ inhibi-
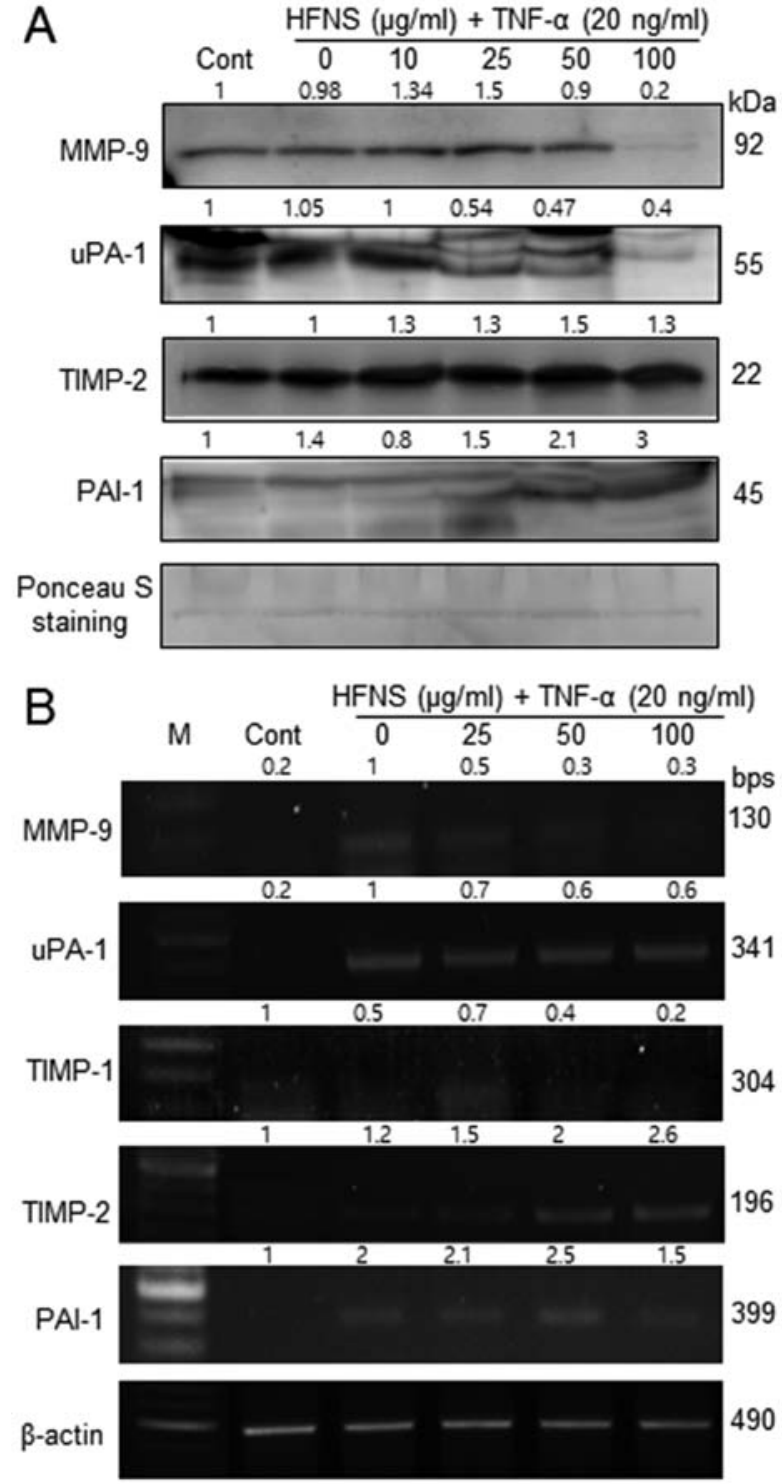

Figure 4. Effects of HFNS on expression of TNF- $\alpha$-induced metastatic molecules. (A) Immunoblotting for metastatic regulatory proteins, MMP-9, uPA-1, TIMP-2 and PAI-1 using concentrated culture supernatant from TNF- $\alpha$-stimulated MDA-MB-231 cells that had been treated with HFNS at the indicated concentrations for $18 \mathrm{~h}$. Equal protein loading sample was confirmed by Ponceau S staining of the membrane prior to immunoblotting. (B) Effects of HFNS on the metastatic molecule transcript levels, as determined by semi-quantitative RT-PCR. RT-PCR for $\beta$-actin was performed in parallel, displaying an equal amount of total RNA in the sample. Relative expression fold-changes were calculated based on densitometric scanning data of each band, and are shown on top of the bands.

tion (Fig. 6B). The binding activity of AP-1 was sustained at first and then declined to $27.1 \%$ of that in the TNF- $\alpha$-treated control after treatment with $200 \mu \mathrm{g} / \mathrm{ml}$ HFNS (Fig. 6B). Based on these results, it is plausible that HFNS treatment inhibits the binding of transcription factors to their DNA response element in response to TNF- $\alpha$ signaling, leading to downregulation of MMP-9 expression.

\section{Discussion}

Regulation of metastasis in breast cancer has been a major goal for successful treatment because most breast cancer-related 


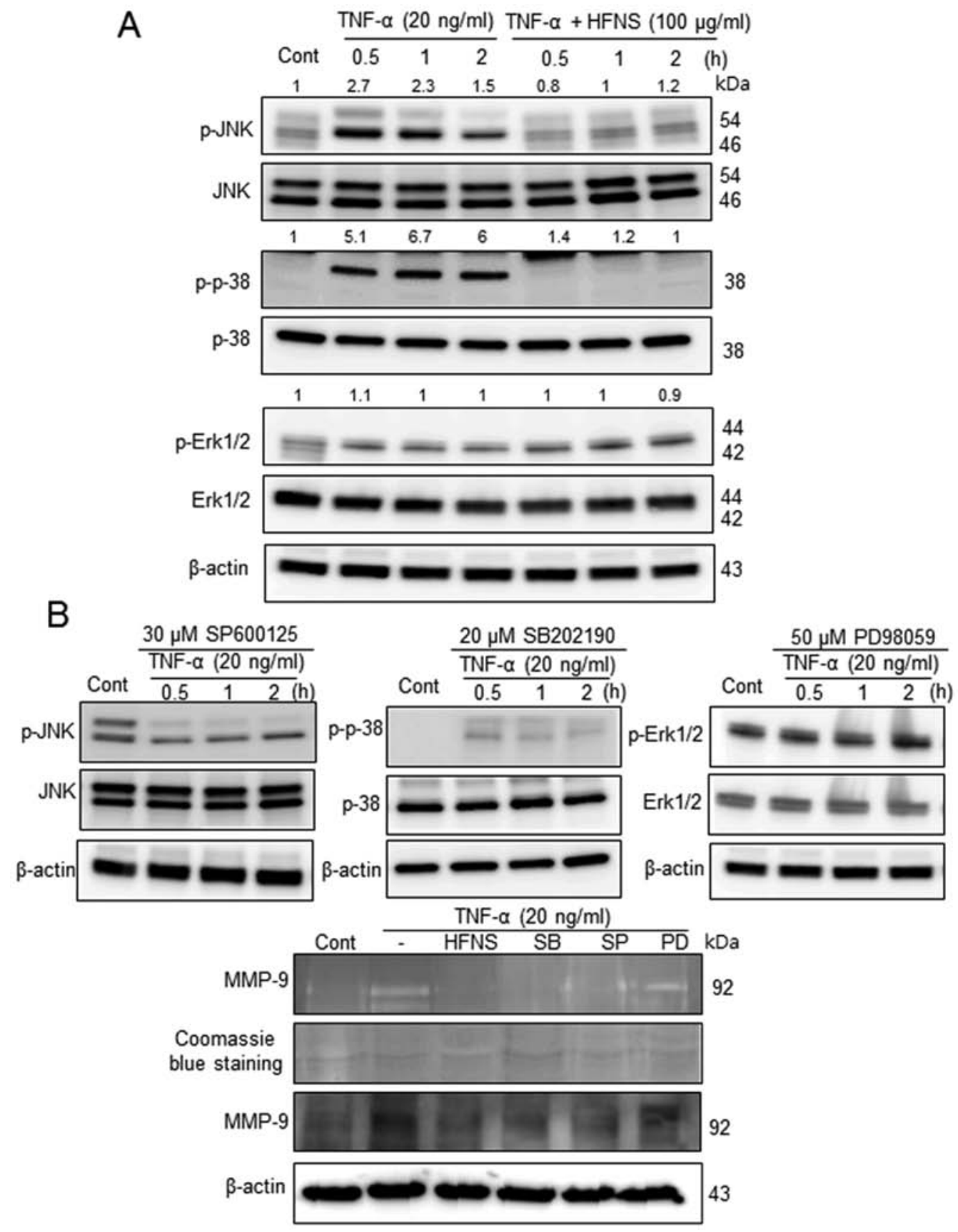

Figure 5. The inhibitory effects of HFNS on TNF- $\alpha$-stimulated MAP kinases that regulate MMP-9. Immunoblotting of phospho-JNK1/2 (P-JNK1/2), phospho-p38 (P-p38), and phospho-ERK1/2 (P-ERK1/2) in MDA-MB-231 cells. (A) Cells were pre-incubated with $100 \mu \mathrm{g} / \mathrm{ml}$ HFNS for the indicated time and were then stimulated with TNF- $\alpha$. (B) Cells were pretreated with SP600125 (30 $\mu \mathrm{M}$, JNK1/2 inhibitor), SB202190 (20 $\mu \mathrm{M}$, p38 MAPK inhibitor), or PD98059 $(50 \mu \mathrm{M}$, MEK1-ERK1/2 inhibitor) for $2 \mathrm{~h}$ and were then stimulated with TNF- $\alpha$ for the indicated time. Each blot was stripped and reprobed with anti-JNK1/2, p-38, or ERK1/2 antibody to correct for differences in protein levels. Medium conditioned by, and lysates of MDA-MB-231 cells that had been treated with HFNS or the above inhibitors were evaluated by gelatin zymography and immunoblot for MMP-9, respectively. Densitometric scanning data after correction for actin loading control are shown on top of the bands. Immunoblotting of each protein was done at least twice using independently prepared lysates and the results were similar. Representative data from a single experiment are shown.

deaths are due to advanced disease and progressive metastasis. The present study first revealed that HFNS prevents invasive potential of the TNF- $\alpha$ activated human MDA-MB-231 breast cancer cells; regulation of invasion is important to prevent tumor reoccurrence. HFNS treatment significantly induced inhibition of cell proliferation and migration of MDA-MB-231 cells. This correlated with a decrease in protein levels of MMP-9, and UPA-1, leading to inhibition of these protease activities; concurrently, levels of TIMP-2, and PAI-1, which are involved in the MAPK signaling pathway were upregulated. In addition, we demonstrated that HFNS suppressed TNF- $\alpha$-mediated MMP-9 activation by decreasing AP-1 or NFאB DNA-binding activity.

As described in previous invasive model studies using breast cancer cells, the protective activities of natural products against metastasis were proposed to be related to regulation of MMPs and TIMPs, and indicated a correlation between MMP expression levels and aggressiveness of tumor cell 
A
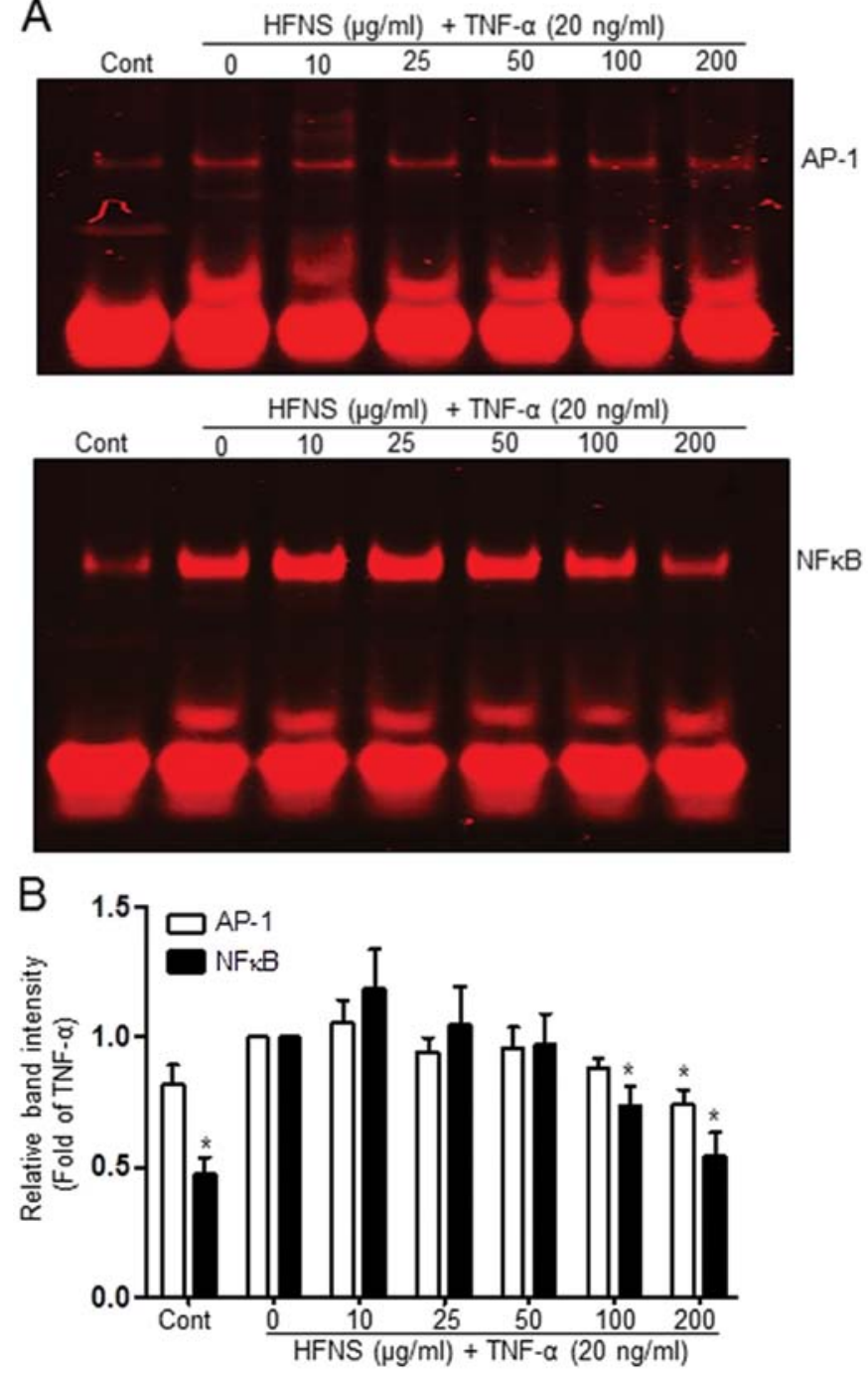

Figure 6. The inhibitory effects of HFNS on AP-1 and NFKB DNA-binding in TNF- $\alpha$-stimulated MDA-MB-231 cells. (A) DNA-binding activity of AP-1 or NFKB in TNF- $\alpha$-stimulated cells that had been treated with HFNS at the indicated concentration was determined by an electrophoretic mobility shift assay (EMSA). Nuclear extracts were incubated with IRDye-700-labeled NF- $\kappa$ oligonucleotide. Representative EMSA data are shown. (B) Relative band intensity was calculated based on densitometric scanning data of each band and is shown as a bar graph. "Significantly different $(\mathrm{P}<0.05)$ compared with only TNF- $\alpha$-treated controls, by one-way ANOVA followed by Dunnett's test. Similar results were observed in two independent experiments.

growth and metastatic potential of such cells $(3,9,11,14,33)$. Therefore, inhibition of invasion mediated by MMPs and uPA-1 could be an important strategy in the prevention of cancer metastasis. Among MMPs, MMP-9 and MMP-2 are considered to play critical roles in tumor invasion and metastasis (34). Our present study findings also demonstrated that HFNS decreased the activity or protein levels of MMP-9 in a dose- and time-dependent manner. In contrast, the treatment with HFNS had no effect on MMP-2 expression and activity in TNF- $\alpha$-stimulated MDA-MB-231 cells. This may be due to tighter regulation of MMP-2; in contrast, other zymogen MMPs are cleaved and activated, and show the ability to activate themselves or other members of this family. MMP-2 is the most commonly expressed MMP in normal tissues (34). Furthermore, differences between tissues and cell types can account for variation of activated MMPs, at least in part, although the expression and secretion of MMPs is controlled in a similar manner in the MAPKs signaling pathways (35). For example, our previous results showed that HFNS exhibited anticancer effect against MDA-MB 231 cells, while having no significant effect on other cancer cell lines, viz., HeLa (cervical carcinoma), HT29 (colonic adenocarcinoma), and breast MCF-7 (breast adenocarcinoma) (27).

Additionally, a number of dietary phytochemicals including extracts or single compounds derived from natural products have been found to target regulatory proteins, including $\mathrm{NF} K \mathrm{~B}$, AP-1, and MAPKs. Some studies have reported that the cisacting elements of human MMP-9 include NFkB, SP-1 and AP-1 elements $(13,21,29)$; thus, exposure to phytochemicals may cause DNA binding activities of $\mathrm{NF \kappa B}$, or AP-1, which can then regulate MMP-9 expression (35). Interestingly, our present results showed that the binding activity of both AP-1 and $\mathrm{NF \kappa B}$ was increased in TNF- $\alpha$-stimulated human breast cancer MDA-MB-231 cells. HFNS treatment significantly suppressed the TNF- $\alpha$-induced increase in the binding activity of both $\mathrm{AP}-1$ and $\mathrm{NF} \kappa \mathrm{B}$, confirming transcriptional regulation of MMP-9 via motifs corresponding to NFKB or AP-1 binding sites. We also demonstrated that HFNS treatment inhibited phosphorylation of $\mathrm{p} 38$, and JNK1/2 and that this resulted in a concurrent reduction in the levels of MMPs and uPA-1, indicating a possible mechanism of inhibition of MMPs or uPA-1 synthesis by HFNS. These results present the first systematic investigation of the molecular mechanism underlying the antimetastatic effects of HFNS. These observations confirm and expand the reported anticancer action of $N$. sublateritium.

Functional compounds identified in N. sublateritium are predominantly polysaccharides, triterpenoids, steroids and lipid molecules such as ceramide $(24,25,36)$. HFNS contains non-polar compounds (27), including tripenoid, clavaric acid, with antitumor activity, which has been shown to significantly inhibit the metastatic ability of MDA-MB-231 cells, which represent TNBC. For effective targeted therapy against TNBC, it has been suggested that chemotherapy be used as first-line therapy (37). Because therapeutic options in both early and late stage breast cancer are significantly affected by the expression of the estrogen receptor, progesterone receptor, and HER-2/ Neu. Given the lack of established molecular targets and the adverse clinical outcome typical in patients with TNBC, there is a clear need for continued development of therapies using chemotherapeutic agents derived from natural products.

In conclusion, HFNS treatment inhibits metastatic steps including migration and invasion in TNF- $\alpha$-stimulated MDA-MB-231 cells. This is achieved by regulation of the activities of migration and invasion-associated proteinases and their inhibitors. The anti-metastatic effect of HFNS is mediated by suppression of MAPKs signaling pathways and $\mathrm{NF \kappa B} /$ AP-1 DNA-binding activities. Taken together, our results indicated that HFNS may be a potential therapeutic approach to the treatment of TNBC.

\section{Acknowledgements}

This study was supported by the National Research Foundation of Korea (NRF) grant funded by the Ministry of Science, ICT and Future Planning (2012R1A1A3015385, 2007-0054932), 
Korea. This study was also supported by 'Forest Science \& Technology Projects (no. S120911L110000)' Korea Forest Service (KFS).

\section{References}

1. Jemal A, Bray F, Center MM, Ferlay J, Ward E and Forman D: Global cancer statistics. CA Cancer J Clin 61: 69-90, 2011.

2. Kreusel KM,Bechrakis NE, Wiegel T, Krause L and Foerster MH: Incidence and clinical characteristics of symptomatic choroidal metastasis from lung cancer. Acta Ophthalmol 86: 515-519, 2008

3. Yang HL, Kuo YH, Tsai CT, et al: Anti-metastatic activities of Antrodia camphorata against human breast cancer cells mediated through suppression of the MAPK signaling pathway. Food Chem Toxicol 49: 290-298, 2011.

4. Fidler IJ: Orthotopic implantation of human colon carcinomas into nude mice provides a valuable model for the biology and therapy of metastasis. Cancer Metastasis Rev 10: 229-243, 1991.

5. Yilmaz M, Christofori G and Lehembre F: Distinct mechanisms of tumor invasion and metastasis. Trends Mol Med 13: 535-541, 2007.

6. Sliva D, English D, Lyons D and Lloyd FP Jr: Protein kinase C induces motility of breast cancers by upregulating secretion of urokinase-type plasminogen activator through activation of AP-1 and NF-kappaB. Biochem Biophys Res Commun 290: 552-557, 2002.

7. Zheng H, Takahashi H, Murai Y, et al: Expressions of MMP-2, MMP-9 and VEGF are closely linked to growth, invasion, metastasis and angiogenesis of gastric carcinoma. Anticancer Res 26: 3579-3583, 2006.

8. Westermarck J and Kahari VM: Regulation of matrix metalloproteinase expression in tumor invasion. FASEB J 13: 781-792, 1999.

9. Quaranta M, Daniele A, Coviello M, et al: MMP-2, MMP-9, VEGF and CA 15.3 in breast cancer. Anticancer Res 27: 3593-3600, 2007.

10. Folgueras AR, Pendas AM, Sanchez LM and Lopez-Otin C: Matrix metalloproteinases in cancer: from new functions to improved inhibition strategies. Int J Dev Biol 48: 411-424, 2004.

11. Look M, van Putten W, Duffy M, et al: Pooled analysis of prognostic impact of UPA and PAI-1 in breast cancer patients. Thromb Haemost 90: 538-548, 2003.

12. Rosen EM, Goldberg ID, Liu D, et al: Tumor necrosis factor stimulates epithelial tumor cell motility. Cancer Res 51: 5315-5321, 1991.

13. Hagemann T, Wilson J, Kulbe $\mathrm{H}$, et al: Macrophages induce invasiveness of epithelial cancer cells via NF-kappa B and JNK. J Immunol 175: 1197-1205, 2005.

14. Chazaud B, Ricoux R, Christov C, Plonquet A, Gherardi RK and Barlovatz-Meimon G: Promigratory effect of plasminogen activator inhibitor-1 on invasive breast cancer cell populations. Am J Pathol 160: 237-246, 2002

15. Stetler-Stevenson WG: Tissue inhibitors of metalloproteinases in cell signaling: metalloproteinase-independent biological activities. Sci Signal 1: re6, 2008.

16. Lijnen HR: Pleiotropic functions of plasminogen activator inhibitor-1. J Thromb Haemost 3: 35-45, 2005.

17. Rose P, Huang Q, Ong CN and Whiteman M: Broccoli and watercress suppress matrix metalloproteinase- 9 activity and invasiveness of human MDA-MB-231 breast cancer cells. Toxicol Appl Pharmacol 209: 105-113, 2005.

18. Choi S and Singh SV: Bax and Bak are required for apoptosis induction by sulforaphane, a cruciferous vegetable-derived cancer chemopreventive agent. Cancer Res 65: 2035-2043, 2005

19. Ho YC, Yang SF, Peng CY, Chou MY and Chang YC: Epigallocatechin-3-gallate inhibits the invasion of human oral cancer cells and decreases the productions of matrix metalloproteinases and urokinase-plasminogen activator. J Oral Pathol Med 36: 588-593, 2007.
20. Seo HS, DeNardo DG, Jacquot Y, et al: Stimulatory effect of genistein and apigenin on the growth of breast cancer cells correlates with their ability to activate ER alpha. Breast Cancer Res Treat 99: 121-134, 2006

21. Jiang J, Grieb B, Thyagarajan A and Sliva D: Ganoderic acids suppress growth and invasive behavior of breast cancer cells by modulating AP-1 and NF-kappaB signaling. Int J Mol Med 21: 577-584, 2008.

22. Sliva D, Jedinak A, Kawasaki J, Harvey K and Slivova V: Phellinus linteus suppresses growth, angiogenesis and invasive behaviour of breast cancer cells through the inhibition of AKT signalling. Br J Cancer 98: 1348-1356, 2008.

23. Kim HG, Yoon DH, Lee WH, et al: Phellinus linteus inhibits inflammatory mediators by suppressing redox-based NF-kappaB and MAPKs activation in lipopolysaccharide-induced RAW 264.7 macrophage. J Ethnopharmacol 114: 307-315, 2007.

24. Godio RP, Fouces R, Gudina EJ and Martin JF: Agrobacterium tumefaciens-mediated transformation of the antitumor clavaric acid-producing basidiomycete Hypholoma sublateritium. Curr Genet 46: 287-294, 2004.

25. Godio RP, Fouces R and Martin JF: A squalene epoxidase is involved in biosynthesis of both the antitumor compound clavaric acid and sterols in the basidiomycete $H$. sublateritium. Chem Biol 14: 1334-1346, 2007.

26. Godio RP and Martin JF: Modified oxidosqualene cyclases in the formation of bioactive secondary metabolites: biosynthesis of the antitumor clavaric acid. Fungal Genet Biol 46: 232-242, 2009.

27. Choi S, Jang HJ, Choi JY, Kim MS, Lee YR, Kim HS, Choi SW, Jeon BH, Won SI, Kim TW and Choi JW: Antioxidant and anticancer activity of fractions of the ethanol extract of Naematoloma sublateritium. J Med Plants Res 6: 9, 2012.

28. Lee YR, Kim KM, Jeon BH, Choi JW and Choi S: The n-butanol fraction of Naematoloma sublateritium suppresses the inflammatory response through downregulation of NF-kappaB in human endothelial cells. Int J Mol Med 29: 801-808, 2012.

29. Kajanne R, Miettinen P, Mehlem A, et al: EGF-R regulates MMP function in fibroblasts through MAPK and AP-1 pathways. J Cel Physiol 212: 489-497, 2007.

30. Cohen M, Meisser A, Haenggeli L and Bischof P: Involvement of MAPK pathway in TNF-alpha-induced MMP-9 expression in human trophoblastic cells. Mol Hum Reprod 12: 225-232, 2006.

31. Leber TM and Balkwill FR: Regulation of monocyte MMP-9 production by TNF-alpha and a tumour-derived soluble factor (MMPSF). Br J Cancer 78: 724-732, 1998.

32. Stuelten CH, DaCosta Byfield S, Arany PR, Karpova TS, StetlerStevenson WG and Roberts AB: Breast cancer cells induce stromal fibroblasts to express MMP-9 via secretion of TNF-alpha and TGF-beta. J Cell Sci 118: 2143-2153, 2005.

33. Bachmeier BE, Nerlich AG, Lichtinghagen $R$ and Sommerhoff CP: Matrix metalloproteinases (MMPs) in breast cancer cell lines of different tumorigenicity. Anticancer Res 21: 3821-3828, 2001.

34. John A and Tuszynski G: The role of matrix metalloproteinases in tumor angiogenesis and tumor metastasis. Pathol Oncol Res 7: $14-23,2001$.

35. Lee EJ, Kim WJ and Moon SK: Cordycepin suppresses TNF-alpha-induced invasion, migration and matrix metalloproteinase- 9 expression in human bladder cancer cells. Phytother Res 24: 1755-1761, 2010.

36. Yaoita Y, Matsuki K, Iijima T, et al: New sterols and triterpenoids from four edible mushrooms. Chem Pharm Bull 49: 589-594, 2001.

37. Chavez KJ, Garimella SV and Lipkowitz S: Triple negative breast cancer cell lines: one tool in the search for better treatment of triple negative breast cancer. Breast Dis 32: 35-48, 2010. 